\title{
The contribution of CXCL12-expressing radial glia cells to neuro-vascular patterning during human cerebral cortex development
}

\author{
Mariella Errede ${ }^{\dagger}$, Francesco Girolamo ${ }^{\dagger}$, Marco Rizzi, Mirella Bertossi, Luisa Roncali and \\ Daniela Virgintino *
}

Department of Basic Medical Sciences, Neurosciences and Sensory Organs, University of Bari School of Medicine, Bari, Italy

\section{Edited by:}

Norman Ruthven Saunders,

University of Melbourne, Australia

\section{Reviewed by:}

Kjeld Møllgård, University of

Copenhagen, Denmark

Udo Schumacher, University of

Hamburg, Germany

\section{*Correspondence:}

Daniela Virgintino, Human Anatomy and Histology Unit, Department of

Basic Medical Sciences,

Neurosciences, and Sensory

Organs, Bari University Medical

School, Piazza Giulio Cesare,

Policlinico-70124 Bari, Italy

e-mail: daniela.virgintino@uniba.it

tThese authors have contributed equally as first authors.
This study was conducted on human developing brain by laser confocal and transmission electron microscopy (TEM) to make a detailed analysis of important features of blood-brain barrier (BBB) microvessels and possible control mechanisms of vessel growth and differentiation during cerebral cortex vascularization. The BBB status of cortex microvessels was examined at a defined stage of cortex development, at the end of neuroblast waves of migration, and before cortex lamination, with BBB-endothelial cell markers, namely tight junction (TJ) proteins (occludin and claudin-5) and influx and efflux transporters (Glut-1 and P-glycoprotein), the latter supporting evidence for functional effectiveness of the fetal BBB. According to the well-known roles of astroglia cells on microvessel growth and differentiation, the early composition of astroglia/endothelial cell relationships was analyzed by detecting the appropriate astroglia, endothelial, and pericyte markers. GFAP, chemokine CXCL12, and connexin 43 (Cx43) were utilized as markers of radial glia cells, CD105 (endoglin) as a marker of angiogenically activated endothelial cells (ECs), and proteoglycan NG2 as a marker of immature pericytes. Immunolabeling for CXCL12 showed the highest level of the ligand in radial glial (RG) fibers in contact with the growing cortex microvessels. These specialized contacts, recognizable on both perforating radial vessels and growing collaterals, appeared as CXCL12-reactive en passant, symmetrical and asymmetrical, vessel-specific RG fiber swellings. At the highest confocal resolution, these RG varicosities showed a CXCL12-reactive dot-like content whose microvesicular nature was confirmed by ultrastructural observations. A further analysis of $R G$ varicosities reveals colocalization of CXCL12 with $\mathrm{Cx} 43$, which is possibly implicated in vessel-specific chemokine signaling.

Keywords: neuroangiogenesis, blood-brain barrier, tight junctions, transporters, radial glia, chemokine CXCL12, connexin 43 , human fetus

\section{INTRODUCTION}

Radial glial (RG) cells were first described in the developing CNS by Magini and Ramón y Cajal in the late 19th century (Bentivoglio and Mazzarello, 1999). Their function as scaffolding for neuroblast migration during cortical histogenesis was postulated and demonstrated by Rakic in the early 1970s (Rakic, 1971, 1972) and then, at the beginning of the new millennium, their role as neuronal and glial precursors in the developing CNS was definitively demonstrated (Malatesta et al., 2000; Malatesta and Götz, 2013). The evidence that RG cells fulfill many functions has attracted new attention to these cells and new discoveries about their diverse functions in the developing brain are rapidly accumulating.

\footnotetext{
Abbreviations: $\mathrm{BBB}$, blood-brain barrier; CD105, endoglin; CNS, Central Nervous System; Coll IV, collagen type IV; Cx43, connexin 43; CXCL12, C-X-C motif chemokine 12; EC, endothelial cells; GFAP, glial fibrillary acidic protein; Glut-1, glucose transporter isoform 1; MVs, microvesicles; NG2, nerve/glial antigen 2; P-gp, P-glycoprotein; RG, radial glia; TJ, tight junction.
}

RG cells differ taxonomically in primates and other mammalian species due to differences in their involvement in neurogenesis, and the timing and region of their appearance, as regards the expression of typical RG immunomarkers (Howard et al., 2008; Xu et al., 2014). For example, in humans, the intermediate filament proteins, glial fibrillary acidic protein (GFAP), and vimentin, are expressed concomitantly in RG from the start of neurogenesis (Choi and Lapham, 1978; Virgintino et al., 1998; Howard et al., 2006). In contrast, in rodents, RG cells undergo a more protracted maturation and become GFAP-positive only at late fetal stages, after neurogenesis is complete, and vimentin is no longer detectable (Rickmann and Wolff, 1985). Moreover, in human telencephalon, due to the larger size of the cerebral cortex compared with the rodent cortex, a "mature" GFAP-expressing RG precociously develops long shafts that may reach a length of $3000-7000 \mu \mathrm{m}$ and show early, special vascular relations (Rakic, 1972; Virgintino et al., 1998).

Pioneering studies have demonstrated that angiogenically formed microvessels invade the developing brain by perforating 
Table 1 | Synopsis of CXCL12 and CXCR4/CXCR7 immunoreactivity in developing brain.

\begin{tabular}{|c|c|c|c|}
\hline Cell type & CXCL12 & CXCR4 & CXCR7 \\
\hline Radial glia cells & cytoplasm high & - & - \\
\hline Perivascular astrocytes & cytoplasm high & - & - \\
\hline Neuroblasts & - & nucleus high & nucleus high \\
\hline Endothelial cells & cytoplasm low & - & - \\
\hline Pericytes & - & cytoplasm high & cytoplasm ${ }^{\text {high }}$ \\
\hline
\end{tabular}

Modified from Virgintino et al. (2013).

the basement membrane and penetrating through the external glial limiting membrane to supply the developing nervous tissue, under the control of a concentration gradient of soluble growth factors (Risau et al., 1988; Risau and Wolburg, 1990; Engelhardt and Risau, 1995). In humans the growing microvessels arrange themselves according to geometrically precise paths that parallel the $\mathrm{RG}$ arrangement, taking on a common radial pattern and forming mutual, multiple contacts (Bär, 1980; MarinPadilla, 1985; Virgintino et al., 1998; Rakic, 2007; Marín-Padilla, 2012). In recent years it has become increasingly evident that the role of RG cells during brain vascularization may be more specific than was previously thought. In fact, besides a simple activity providing tracks for growing vessels, RG cells have been suggested to be the source of factors such as vascular endothelial growth factor (VEGF) and Wnt, that intertwine with each other and other angiogenic pathways to facilitate the guidance of penetrating microvessels, stimulate proliferation of endothelial cells (ECs) and sustain vessel stabilization (Liebner and Plate, 2010; Bussmann et al., 2011; Quaegebeur et al., 2011).

During human cerebral cortex vascularization, subsets of RG cells and perivascular astrocytes have been demonstrated, showing high levels of chemokine CXCL12 expression (Virgintino et al., 2013). This chemokine, also known as stromal-derived factor-1 (SDF-1), plays multiple roles in CNS development, its expression in the brain being involved in neural progenitor differentiation, and neuronal cell migration (Tiveron et al., 2006; Peng et al., 2007; Stumm and Höllt, 2007; Li et al., 2008; Tiveron and Cremer, 2008). Moreover, cells of neural crest origin, located in the developing, innermost layer of the meninges, have been demonstrated to be involved in neurogenesis, secreting molecular cues including chemokine CXCL12, that seem to regulate cortical interneuron settlement, and Cajal-Retzius cell tangential migration (Stumm et al., 2003; Borrell and Marín, 2006; Paredes et al., 2006; Li et al., 2008; Siegenthaler et al., 2009).

In addition, CXCL12 and its receptor CXCR4 (C-X-C chemokine receptor) belong to a restricted group of pro-angiogenic molecules that, albeit within a limited developmental window, display a neuro-specific angiogenic activity (Bussmann et al., 2011; Quaegebeur et al., 2011). Overall, these data are consistent with previous observations of human developing cerebral cortex, which have described CXCR4/CXCR7-reactive neuroblasts and subsets of CXCL12 RG cells and astrocytes in close association with CXCR4/CXCR7-reactive microvascular ECs and pericytes (Virgintino et al., 2013; see also Table 1). Accordingly, a model
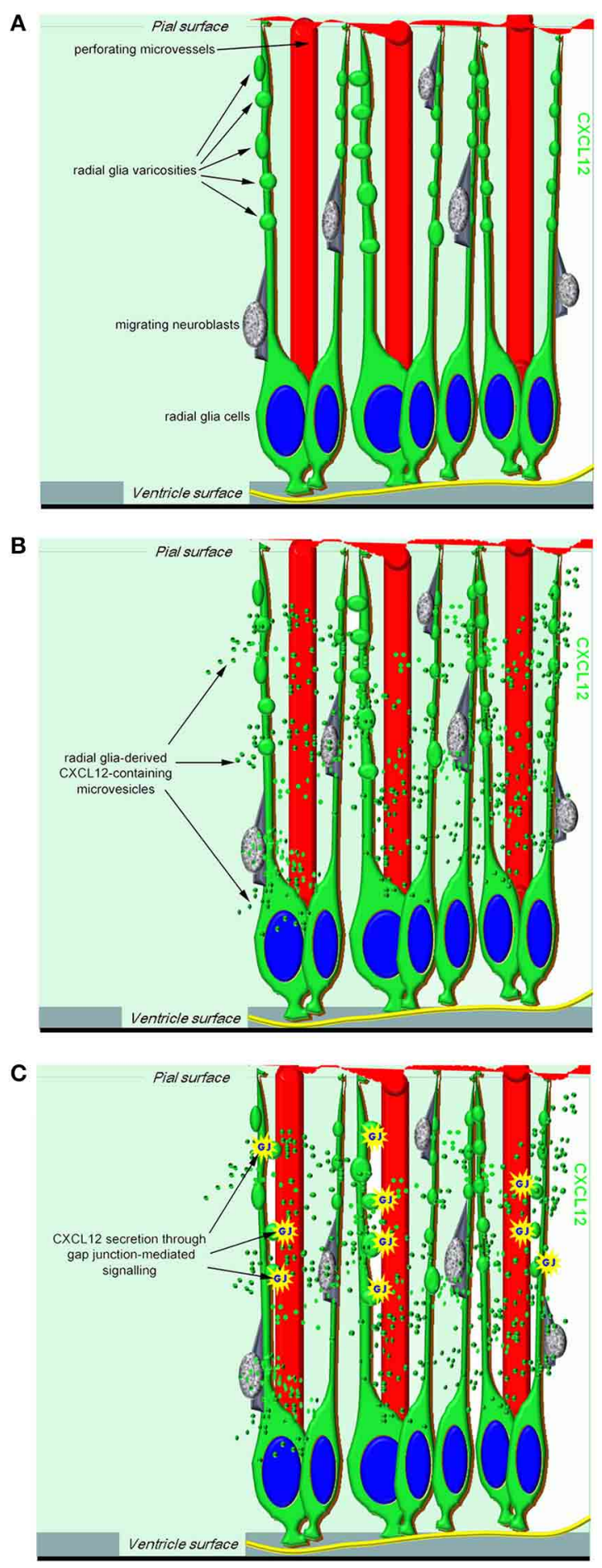

FIGURE 1 | A proposed model of RG-derived CXCL12 regulation of cerebral cortex development and vascularization. (A) In the working model, CXCL12 radial glia cells have a central role not only in neurogenesis and neuroblast migration but also in neuroangiogenesis, being ideally positioned to coordinate neuro-vascular cerebral cortex patterning. (B) Radial glia-derived CXCL12-containing microvesicles may convey their signal to the ECs of growing microvessels. (C) One potential mechanism by which CXCL12 secretion can be modulated in radial glia cells is through gap junction-mediated signaling. 
of synchronized neuro-vascular patterning centered on CXCL12 RG cells has been proposed (Figure 1) and appears to be supported by the present results that have identified, by parallel laser confocal and electron microscopy analyses, RG-microvessel subcellular units shaped by RG varicosities containing CXCL12 microvesicles (MVs) and connexin $43(\mathrm{Cx} 43)$ as a regulatory molecule.

\section{MATERIALS AND METHODS HISTOLOGY}

Autopsy specimens of telencephalon were collected from 4 human fetuses spontaneously aborted due to preterm rupture of the placental membranes (22 weeks of gestation). The sampling and handling of human specimens conformed to the ethical rules of the Department of Pathology, Medical School, University of Bari, Italy, and approval was gained from the local Ethics Committee of the National Health System in compliance with the principles stated in the Declaration of Helsinki. The fetal age was estimated on the basis of the crown-rump length and/or pregnancy records (counting from the last menstrual period). At autopsy, the selected fetuses did not reveal macroscopic structural abnormalities and/or malformations of the central nervous system. The dorso-lateral wall of the telencephalic vesicles (future neocortex) was dissected and fixed for $2-3 \mathrm{~h}$ at $4^{\circ} \mathrm{C}$ by immersion in $2 \%$ paraformaldehyde plus $0.2 \%$ glutaraldehyde solution. Specimens were then washed in phosphate buffered saline (PBS, pH 7.6) and serially sectioned by a vibrating microtome. $20 \mu \mathrm{m}$ sections were collected at regular intervals and processed for conventional histological analysis with toluidine blue staining to ascertain the absence of microscopic malformations; all the other sections were stored in PBS plus $0.02 \%$ paraformaldehyde for fluorescence immunolabeling.

\section{IMMUNOFLUORESCENCE AND LASER CONFOCAL MICROSCOPY}

Multiple immunostainings were carried out with the following polyclonal antisera (pAbs) and monoclonal antibodies (mAbs), all diluted in blocking buffer ( $1 \%$ bovine serum albumin and $2 \%$ fetal calf serum in PBS): rabbit pAb anti-Glut 1 , mouse mAb anti-P-gp, mouse $\mathrm{mAb}$ anti-Claudin-5, rabbit $\mathrm{pAb}$ anti-Occludin, mouse $\mathrm{mAb}$ anti-CXCL12/SDF-1, rabbit $\mathrm{pAb}$ anti-CD105, rabbit pAb anti-NG2 (generous gift from W. B. Stallcup, The Burnham Institute for Medical Research, La Jolla, CA, USA), mouse $\mathrm{mAb}$ anti-GFAP, rat $\mathrm{mAb}$ anti-GFAP, rabbit $\mathrm{pAb}$ anti-collagen type IV (Coll IV), rabbit pAb anti-Cx43 (Table 2). After adhesion on polylysine slides (Menzel-Glaser, $\mathrm{GmbH}$, Braunschweig, Germany) by drying for $10 \mathrm{~min}$ at room temperature, the sections were submitted to the following protocols: rehydration with PBS for $5 \mathrm{~min}$ at room temperature or microwave pretreatment in $0.01 \mathrm{M}$ citrate buffer $(\mathrm{pH} 6.0$ ) for $15 \mathrm{~min}$ at $750 \mathrm{~W}$ when required (Table 2 ); incubation with $0.5 \%$ Triton $\mathrm{X}-100$ in PBS for $30 \mathrm{~min}$ at room temperature and with blocking buffer $30 \mathrm{~min}$ at room temperature, with single or combined primary antibodies overnight at $4^{\circ} \mathrm{C}$, then with appropriate fluorophoreconjugated secondary antibodies (Table 2 ). Finally, the sections were washed for $10 \mathrm{~min} \times 3$ in PBS between each step, counterstained with either TO-PRO- $3^{\mathrm{TM}}$ (1:10K dilution; Invitrogen Corporation, Carlsbad, CA, USA) or Sytox ${ }^{\circledR}$ Green (1:5K dilution; Invitrogen), mounted in Vectashield (Vector Laboratories, Inc. Burlingame, CA, USA), and finally sealed with nail varnish. Negative controls were prepared by using primary antibodies to

Table 2 | List of primary and secondary antibodies combined in multiple immunolabelings.

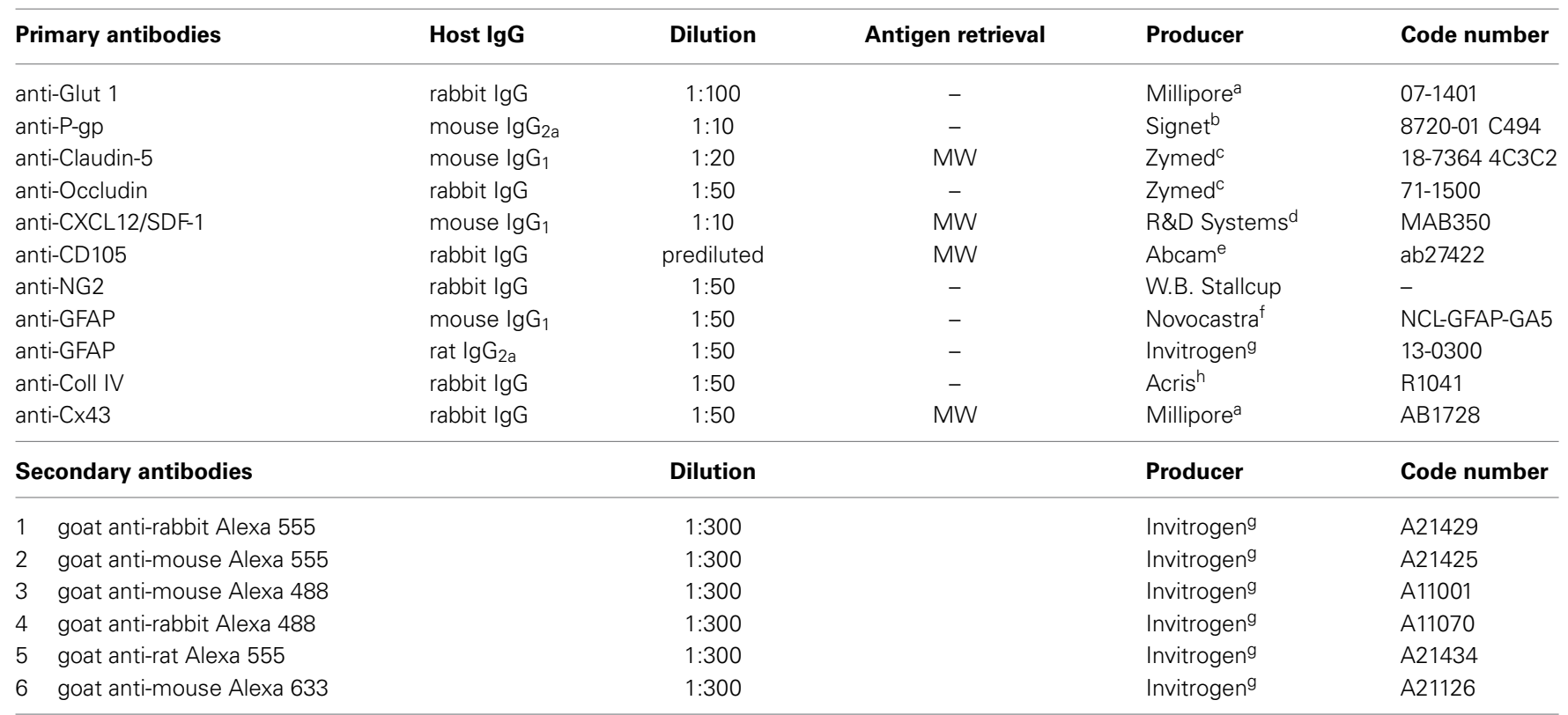

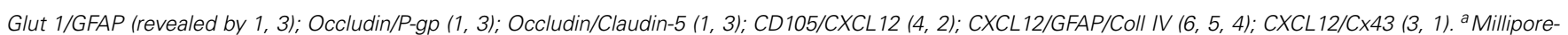
Chemicon; Billerica, MA, USA. 'b Signet Laboratories, Dedham, MA, USA. 'Cymed Laboratories, Invitrogen Corporation, Carlsbad, CA, USA. ${ }^{d}$ R\&D Systems, Minneapolis, MN, USA. ${ }^{e}$ Abcam, Cambridge, UK. ${ }^{f}$ Vision Biosystem Novocastra, Newcastle upon Tyne, UK. ${ }^{9}$ Invitrogen, Eugene, OR, USA. hicris Antibodies $\mathrm{GmbH}$; Herford, Germany. MW, high-temperature microwave pre-treatment of tissue sections. 
stain inappropriate tissues, omitting the primary antibodies, preadsorbing the primary antibodies with an excess of antigen when available, or mismatching the secondary antibodies on appropriate preparations. When not ascertained in previous experiments, the specificity of primary antibodies was tested on tissue sections known to contain the antigen, as positive controls, and applying the same immunostaining protocols described above. Human adult brain sections were used to test the BBB-specific markers (Glut 1, P-gp, Claudin-5, Occludin), Cx43 antibody was tested on human and mouse brain sections and on mouse heart sections, while sections from human tonsils were useful for assessing CXCL12 and CD105, immunoreactivity (control sections were kindly provided by E. Maiorano, Department of Emergency and
Organ Transplantation, Pathological Anatomy Unit, Faculty of Medicine, University of Bari, Bari, Italy). The sections were examined under the Leica TCS SP5 confocal laser-scanning microscope (Leica Microsystems, Mannheim, Germany) using a sequential scan procedure. Confocal images were taken at $250 \mathrm{~nm}$ intervals through the $\mathrm{z}$-axis of the sections. Confocal images were taken with 40X and 63X oil lenses. Z-stacks of serial optical planes (projection images) and single optical planes were analyzed by Leica confocal software (Multicolor Package; Leica Microsystems). The size of RG varicosities and MVs was evaluated with LAS-AF SP5 software (Leica Microsystems) on 63X magnification fields zoomed 3 times. MVs diameter $(\mathrm{nm})$ was measured on single optical planes from CXCL12-labeled sections $(n=18)$ for a total
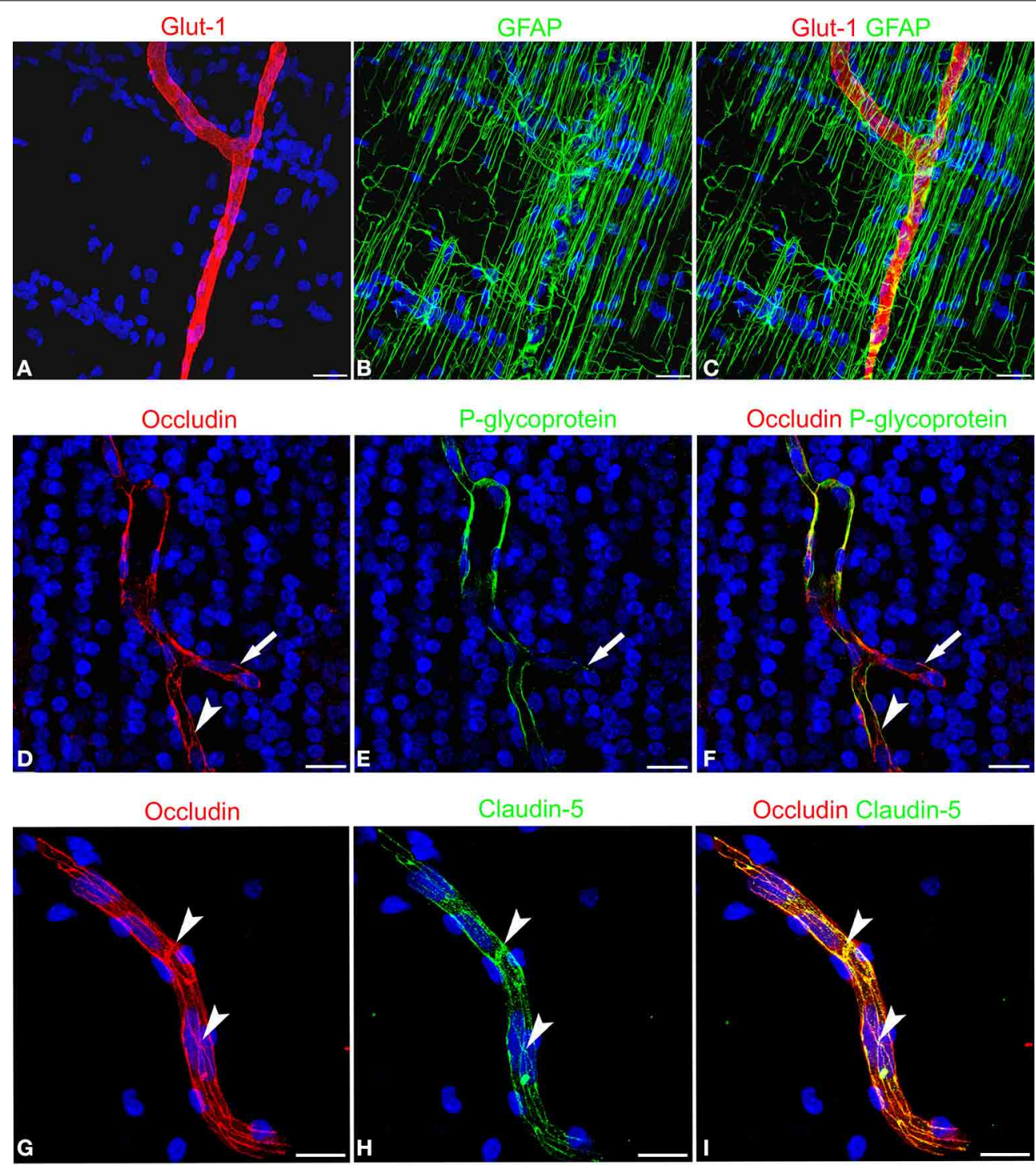

FIGURE 2 | Confocal images of human cerebral cortex at midgestation double labeled with Glut-1/GFAP, occludin/P-glycoprotein, and occludin/claudin-5. (A-C) A radial microvessel surrounded by GFAP-reactive RG fibers is revealed by the Glut-1 reactive endothelial cells. (D-F) On a stem vessel and its collateral (arrow) endothelial P-glycoprotein colocalize with occludin reactivity; note in (E) the lower levels of P-glycoprotein expression on the newly formed vessel branch (arrow) and in (D) and (F) the junctional linear pattern of occludin (arrowhead). (G-I) Occludin appears arranged according to a typical junctional pattern and colocalizes at points with claudin-5 (arrowheads). Bars: A-C and D-F $25 \mu \mathrm{m} ; \mathbf{G}-\mathbf{I} 30 \mu \mathrm{m}$. 


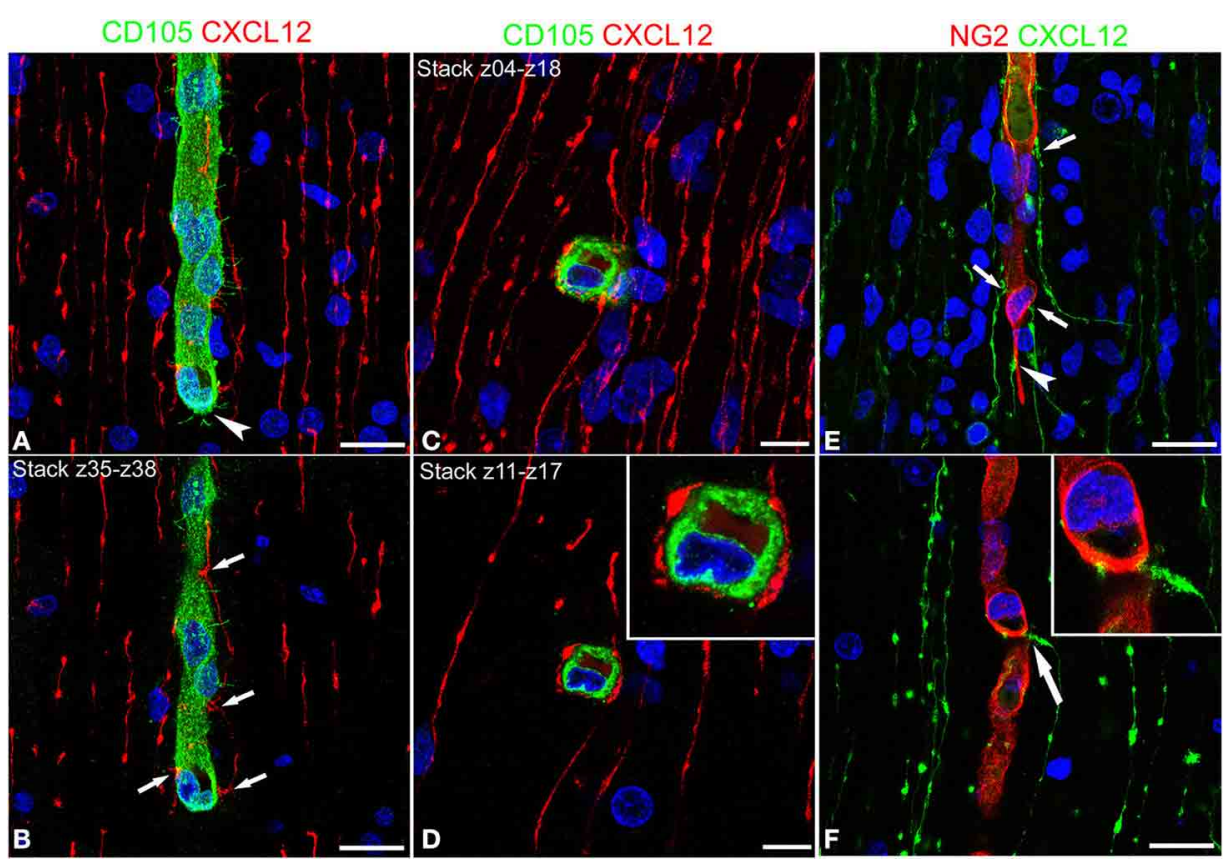

FIGURE 3 | Confocal images of human cerebral cortex at midgestation double labeled with CD105/CXCL12 (A-D) and NG2/CXCL12 (E,F).

CXCL12-reactive RG fibers show evenly spaced varicosities (A) that make contacts at regular intervals (better recognizable on the selection of optical planes z35-z38; B, arrows) with a CD105 labeled, perforating cortex

microvessel; note in (A) the tip endothelial cell on the growing vessel front (arrowhead). (C,D) Transverse view of a vascular branch completely surrounded by CXCL12 RG fibers, whose intimate relationships are better recognizable on a shorter stack of optical planes (z11-z17, D; inset). (E) Multiple CXCL12-reactive varicosities touching the NG2 pericyte cover (arrows) and a pericyte leading process (arrowhead); (F) One CXCL12-labeled varicosity bents to contact the vessel wall (arrow in F; inset). Bars: A,B $20 \mu \mathrm{m} ; \mathbf{C}, \mathbf{D} 10 \mu \mathrm{m} ; \mathbf{E}, \mathbf{F} 20 \mu \mathrm{m}$.

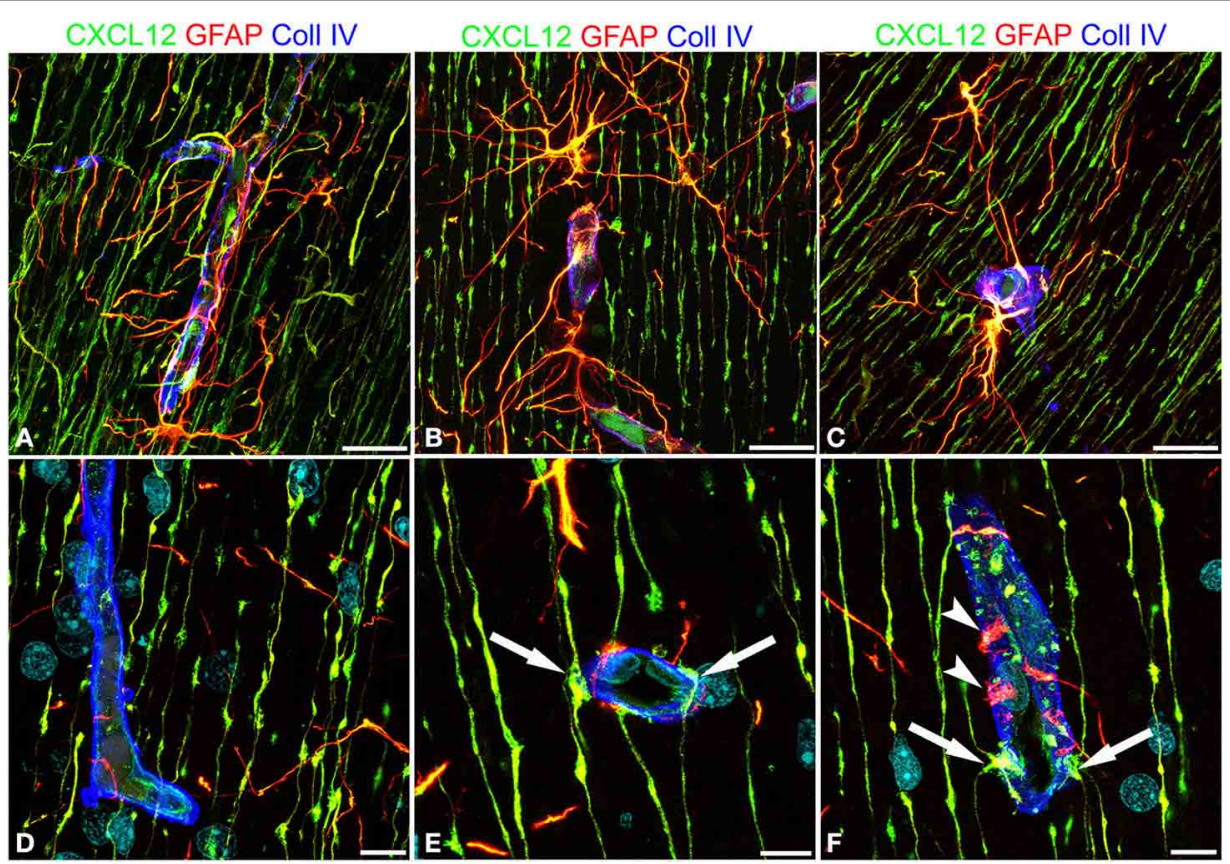

FIGURE 4 | Confocal images of human cerebral cortex at midgestation after multiple labeling with CXCL12, GFAP, and Coll IV. (A-C) GFAP-CXCL12-reactive perivascular astrocytes and CXCL12-reactive RG cells contributing perivascular endings to the microvessel wall revealed by collagen IV (b/ue). (D-F) On selected single optical planes the RG vascular contacts are distinguishable, two en passant, symmetrical varicosities on the vessel wall (E, arrows) and two omega-shaped asymmetrical varicosities on either sides of the vessel profile ( $\mathbf{F}$, arrows); note in (F) classical GFAP-labeled astrocyte end-feet (arrowheads). Bars: A-C $20 \mu \mathrm{m}$; D-F $10 \mu \mathrm{m}$ 


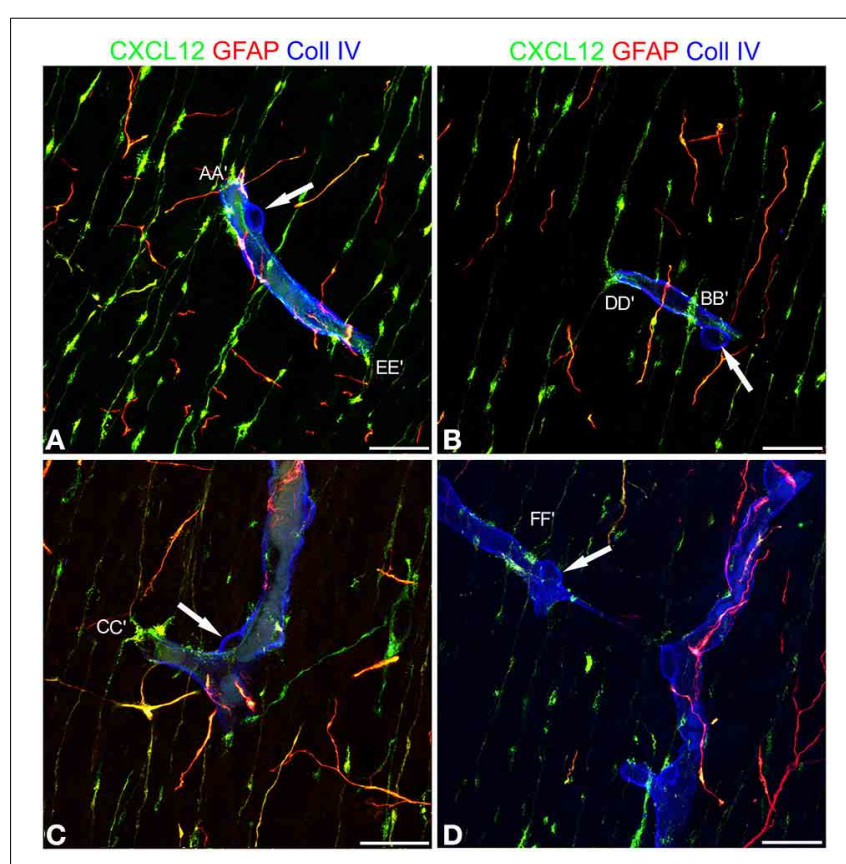

FIGURE 5 | Confocal images of human cerebral cortex at midgestation after multiple labeling with CXCL12, GFAP, and Coll IV. (A-D) A further collection of CXCL12-reactive RG varicosities in contact with the vessel wall, whose Coll IV staining also shows the bulging nuclei of pericytes (arrows in A-D). Single RG-vascular contacts are recognizable in these pictures ( $\mathbf{A A}^{\prime}, \mathbf{B B} \mathbf{B}^{\prime}, \mathbf{C} \mathbf{C}^{\prime}, \mathbf{D} \mathbf{D}^{\prime}, \mathbf{E} \mathbf{E}^{\prime}$, and $\left.\mathbf{F F}^{\prime}\right)$ and are shown as enlarged details in Figure 6. Bars: A-D $20 \mu \mathrm{m}$

of 50 fields. The results were expressed as a "range" of size from a minimum to a maximum value.

\section{TRANSMISSION ELECTRON MICROSCOPY}

Small samples collected from the previously described telencephalon specimens were submitted to electron microscopy procedures. Briefly, samples were fixed in $0.1 \mathrm{M}$ phosphate-buffered $3 \%$ glutaraldehyde, post-fixed in phosphate-buffered $1 \% \mathrm{OsO} 4$, dehydrated in serial alcohols, and embedded in Epon 812. Ultrathin sections were cut with an LKB V ultramicrotome (LKB Bromma, Sollentuna, Sweden), stained with uranyl acetate and lead citrate, and observed under a CM 10 Philips electron microscope (Philips, Eindhoven, The Netherlands).

\section{RESULTS \\ CEREBRAL CORTEX MICROVESSELS SHOW A BBB-SPECIFIC PHENOTYPE}

The expression of blood-brain barrier (BBB)-specific markers was analyzed in microvessels that, at the end of neuronal migration and beginning of cortex lamination, in the fetal age of around midgestation, vascularize the cerebral cortex, radially invading the neural wall from the pial surface to the deeper subcortical layers. Their endothelial lining is characterized by a strong reactivity to fundamental metabolic and efflux barrierspecific transporters, such as the glucose transporter isoform 1, Glut-1, and to a member of the ABC (ATP-binding cassette) superfamily, the multidrug transporter P-glycoprotein (P-gp or
ABCB1). On double staining with Glut-1 and the astroglia marker GFAP, radial vessels appear surrounded by a curtain of GFAPreactive RG fibers and their ECs express high levels of Glut-1 (Figures 2A-C). Cortex stem microvessels appear aligned with rows of neuroblasts and are seen to form their first collaterals, stem vessels and branches being revealed by the endothelial expression of P-gp (Figures 2E,F). The presence of two BBB transporters indirectly implies that tight junction (TJ) formation is in progress in ECs and that the barrier is partially functional. In fact, on double staining with P-gp and the TJ protein occludin, the latter appears highly expressed on both stem vessels and collaterals, and shows a linear, junctional staining pattern (Figures 2D-F). Also on double staining with the TJ protein claudin-5, occludin displays a clearly junctional distribution, whereas a punctate cytoplasmic pattern still prevails for claudin-5 (Figures 2G-I). Overall, these data demonstrate an ongoing process of BBB differentiation in human cerebral cortex microvessels at midgestation.

\section{VESSEL-SPECIFIC CONTACTS OCCUR BETWEEN CXCL12-REACTIVE RG FIBERS AND CORTEX MICROVESSELS}

Cerebral cortex microvessels are also revealed by the endothelial marker CD105, which also allows recognition of the growing front of the invading vessels, that is characterized by CD105-reactive endothelial tip cells (Figures 3A,B). On double immunostaining for CXCL12, CD105 labeled microvessels appear surrounded by palisades of CXCL12-reactive RG fibers and in direct contact with sequences of swellings characterizing the RG fibers (Figures 3A,B) that are also seen in close contact with radial vessel collaterals (Figures 3C,D). Double staining with proteoglycan NG2 antibody as a pericyte marker also demonstrates several points of apposition between regular sequences of RG vascular varicosities and the microvessel wall (Figures 3E,F).

These first observations were extended by triple immunostaining with GFAP and CXCL12, as a classical and a novel marker of RG cells, respectively, and with collagen type IV (Coll IV) as a marker of the vascular basal lamina (Figures $4 \mathrm{~A}-\mathrm{F}$ ). By this staining, in the subcortical layers, where the earliest astrocytes become recognizable, the microvessels appear surrounded by a perivascular subset of astrocytes that express high levels of both GFAP and CXCL12 (see also Virgintino et al., 2013) (Figures 4A,B). On the same sections, RG fibers reveal a lower GFAP immunostaining and a higher staining of CXCL12 (Figures 4A-C). The two markers colocalize on RG vessel-specific varicosities that make en passant contacts maintaining a symmetrical profile, denoted as symmetrical varicosities, or assume an omega-like shape and are therefore indicated as asymmetrical varicosities (Figures 4D-F). In favorable conditions of tissue and antigenicity preservation, and with the opportune setting of laser potency and confocal parameters, the described RG symmetrical and asymmetrical varicosities appear filled by CXCL12-labeled dot-like structures that sometimes display a microvesicular nature (Figures 5A-D, 6A-F, $\mathbf{A}^{\prime}, \mathbf{F}^{\prime}$ ). The CXCL12 MVs are densely packed within varicosities measuring about $1-1.5 \mu \mathrm{m}$ and show a diameter of 100-200 nm (Figures 5A-D, $\left.\mathbf{6 A}-\mathbf{F}, \mathbf{A}^{\prime}-\mathbf{F}^{\prime}\right)$. At sites of vascular contact, CXCL12 densities 

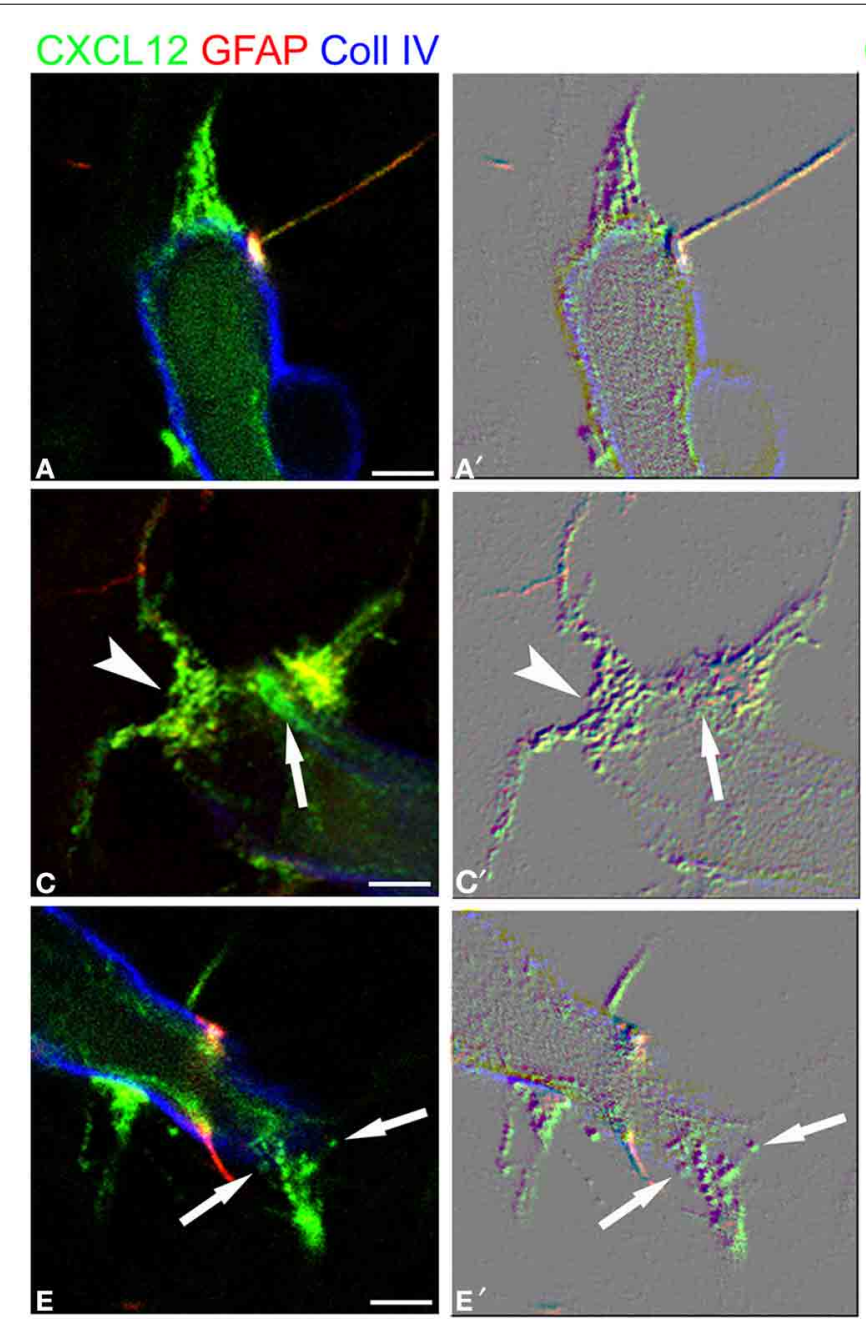

FIGURE 6 | RG-vascular contacts shown in Figure 5, (A-F) and the same pictures rendered with an embossed image filter $\left(\mathbf{A}^{\prime}-\mathbf{F}^{\prime}\right)$. The profile in relief of $\mathrm{MV}$-like subcellular structures is amplified and well-recognizable on the flat surface; note in $\left(\mathbf{A}, \mathbf{A}^{\prime}\right)$ gathered $M V^{\prime}$, in $\left(\mathbf{B}, \mathbf{B}^{\prime}\right)$ an en passant, symmetrical

\section{CXCL12 GFAP Coll IV}
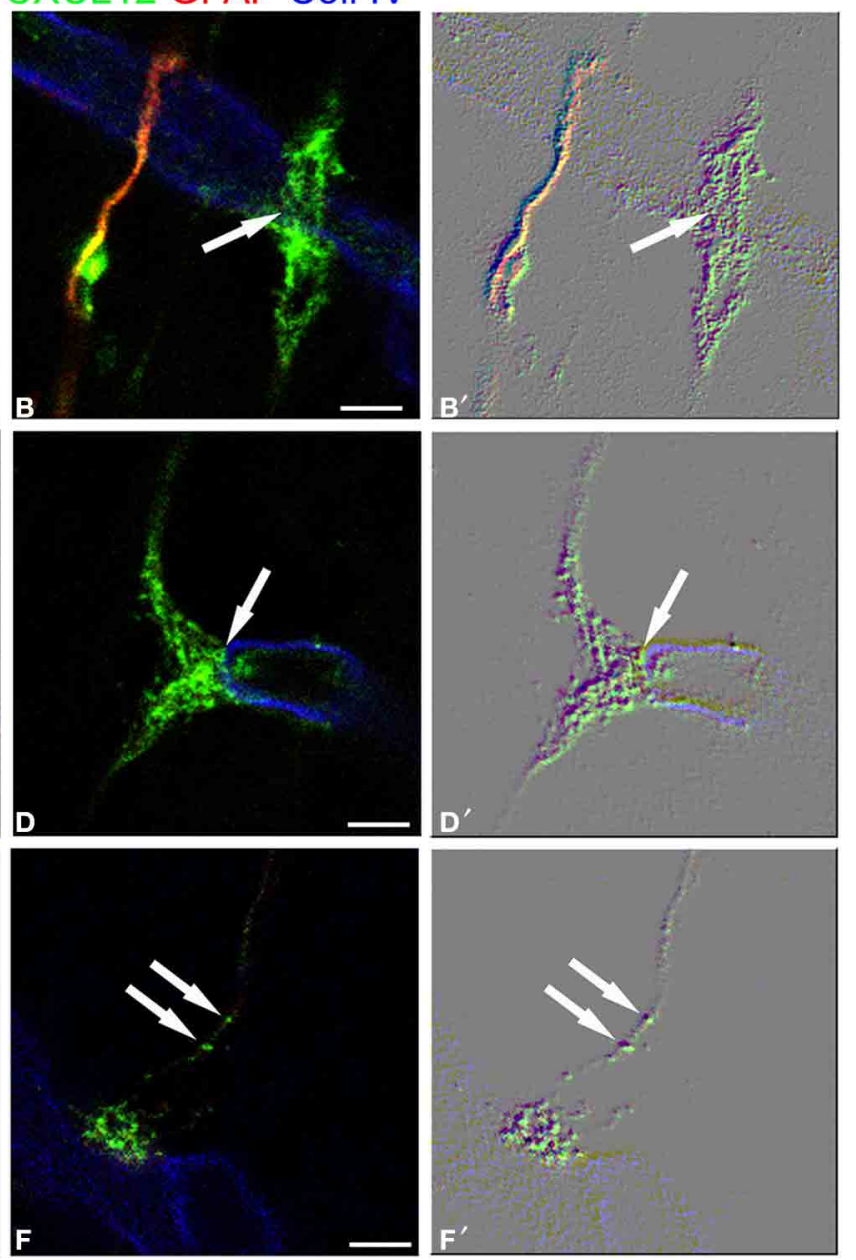

varicosity (arrow), in (C, $\mathbf{C}^{\prime}$ ) an asymmetrical varicosity (arrowhead) and an endothelial CXCL12-reactive density faced by a RG contact (arrow), in (D, $\mathbf{D}^{\prime}$ ) a clearly recognizable MV (arrow), in (E, $\mathbf{E}^{\prime}$ ) released MVs (arrows), and in (F,F') MVs within the RG fiber (arrows). Bars: A-F $2.5 \mu \mathrm{m}$. are also recognizable beneath the Coll IV basal membrane (Figure 6C).

\section{RG VARICOSITY AND MVs ARE CLEARLY REVEALED BY TRANSMISSION ELECTRON MICROSCOPY}

When comparing confocal images of radial microvessels, after triple immunostaining for CXCL12, GFAP, and Coll IV (Figures 7A,B), with similar fields studied by transmission electron microscopy (TEM), some details, appreciated in the former, become clearly defined by ultrastructural observations (Figures 7C,D). The vesicular nature of the subcellular structures observed by confocal microscopy after CXCL12 immunolabeling is confirmed (Figures 7A-D), while RG varicosities and the vascular basal membrane are seen in close contact at several points of the vessel wall (Figures 7C,D). MVs appear homogeneous in size and aligned against the varicosity membrane facing the vessel contact site (Figures 7C,D).

\section{GAP JUNCTION PROTEIN CX43 COLOCALIZES WITH CHEMOKINE CXCL12 IN RG VARICOSITIES}

The presence of $\mathrm{Cx} 43$ was revealed in double immunostaining for CXCL12 and Cx43, the rationale for this approach being sustained by data on Cx43 involvement in RG-guided neuronal migration (Elias et al., 2007; Matsuuchi and Naus, 2013) and by studies on Cx43 in RG cells (Virgintino et al., 2001; Errede et al., 2002). Cx43 plaques are revealed along the RG fibers and concentrate in vessel-contacting RG varicosities, where $\mathrm{Cx} 43$ extensively colocalizes with CXCL12 (Figures 8A-D).

\section{DISCUSSION}

\section{RADIAL GLIAL CELL VARICOSITIES AND CXCL12 MVs INVOLVED IN CEREBRAL CORTEX VASCULARIZATION}

In 1887, when Giuseppe Magini utilized for the first time the Golgi impregnation technique on mammalian developing cerebral cortex, he described "neuroglial cells with very long 


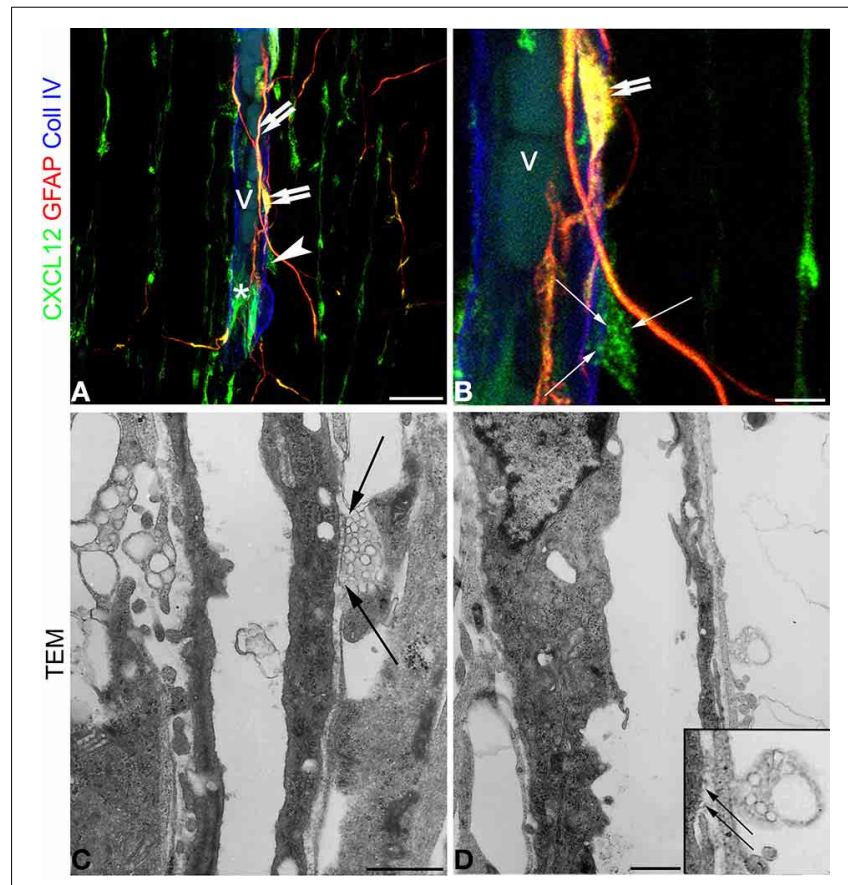

FIGURE 7 | Confocal images (A,B) and transmission electron microscopy (C,D) of human cerebral cortex at midgestation. (A,B) Triple labeling with CXCL12, GFAP, and Coll IV shows the profile of a radial vessel (v) contacted by GFAP/CXCL12-reactive perivascular astrocyte processes (double arrows) and CXCL12-reactive RG fibers (asterisk); a RG varicosity (arrowhead) in contact with the vessel wall is enlarged in (B) and appears filled by CXCL12 labeled MVs (arrows). (C,D) At ultrastructural level, perivascular RG varicosities show their content of membrane-bound MVs regularly aligned with the vessel contact side (C and inset in $\mathbf{D}$; arrows). Bars: A $20 \mu \mathrm{m}$; B $5 \mu \mathrm{m}$; C,D $5 \mu \mathrm{m}$.

and thin filaments bearing numerous varicosities or swellings" (Bentivoglio and Mazzarello, 1999). Subsequently, in 1904, Cajal confirmed the existence of radiating fibers and extended Magini's work, definitely describing "swelling intercalated along the radial glia fibers protoplasmic accumulation” (Ramón y Cajal, 1904). In recent studies on neurogenic RG in rat embryos, DiI-labeled RG cells have shown a "Golgi-like" morphology, including the small varicosities, that have been described as points of cytoplasm accumulation in the flux and reflux of fluid through the cell during mitosis (Weissman et al., 2003; Kriegstein and Alvarez-Buylla, 2009). Surprisingly, CXCL12, a chemokine that accumulates in RG fibers, can show these cellular structures in detail, going beyond the mere profile of cytoplasmic swelling, and instead suggesting a role as specialized cellular sites. RG cells, like cerebellar Bergmann glia and retinal Müller cells, both examples of RG-like glial cells in adult CNS, may display a differential distribution of organelles and membrane domains along their length (Fedoroff and Vernadakis, 1986). The described RG varicosities can be regarded as special compartments of the cell devoted to closely adjoining the vessel wall to form specific vascular contacts.

CXCL12-bearing MVs, as cell-derived MVs (diameter ranging from 0.1 to $1 \mu \mathrm{m}$ ) involved in cell-to-cell communication,

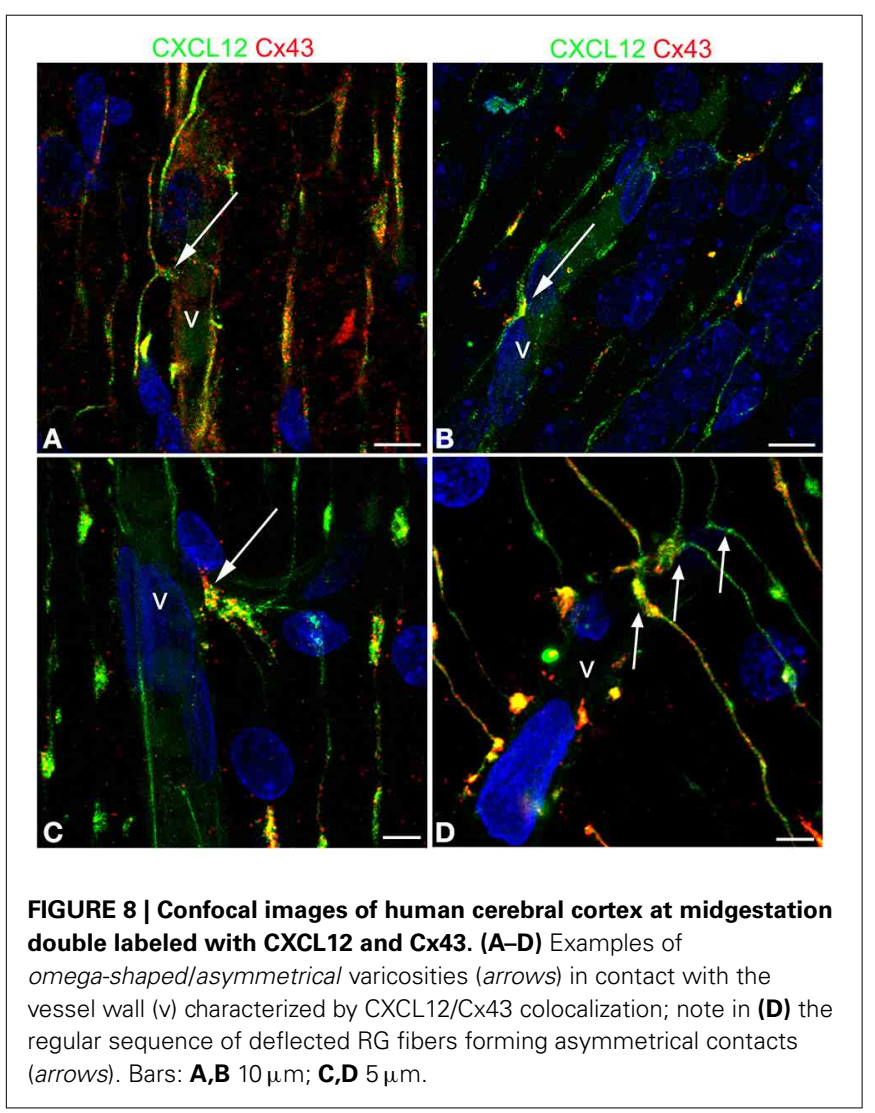

may directly bud from the plasma membrane to convey their membrane-associated bioactive molecule to the target cells (György et al., 2011; Frühbeis et al., 2012; Kalra et al., 2012). It has been demonstrated that cultured astrocytes shed MVs from cell domains interpreted as astrocyte end-feet, which contain angiogenic factors, FGF-2, and VEGF, and membrane associated B1-integrin (Proia et al., 2008), MVs can, therefore, participate in angiogenic events, transferring pro-angiogenic factors to ECs (Boulanger and Tedgui, 2005; Muralidharan-Chari et al., 2010; Martinez and Andriantsitohaina, 2011). Moreover, it has also been shown that tumor-derived MVs released by tumor ECs can be taken up by normal ECs through endocytosis, and promote motility and tube formation, conferring proangiogenic properties to quiescent ECs (Kawamoto et al., 2012). It has been demonstrated that in zebrafish brain and in rat developing retina, chemokine CXCL12 signaling specifically controls the correct pathfinding of newly formed microvessels (Strasser et al., 2010; Unoki et al., 2010; Bussmann et al., 2011; Fujita et al., 2011). Our findings support these roles, suggesting that the chemokine can become available, through the shedding of MVs from RG varicosities, for ligand/receptor interactions on ECs or, alternatively, after MVs endocytosis, for direct EC activation.

\section{CXCL12 VESSEL-SPECIFIC ACTIVITY REGULATED BY CX43 NON-CHANNEL ROLES}

The preliminary results that show a CXCL12/Cx43 colocalization in RG glio-vascular contacts suggest that the release of 
CXCL12 can be regulated by the activation of Cx43 hemichannels, non-junctional structures that can be involved in the release of signaling molecules, and that are a common attribute of cells during development, forming functional hexameric rings before proper gap junctions appear (Nagy et al., 2004; Nielsen et al., 2012; Stehberg et al., 2012; Giaume et al., 2013; Zhou and Jiang, 2014). In fact, during cerebral cortex development, Cx43 displays channel-independent roles also when regulating neuroblast migration (Matsuuchi and Naus, 2013). Moreover, as demonstrated for human bone marrow stromal cells, the secretion of functional CXCL12 by RG cells could be mediated by $\mathrm{Cx} 43$ (Schajnovitz et al., 2011), and Cx43 has been found to regulate CXCL12-mediated Rap1 EC spreading “in vitro" (Machtaler et al., 2011).

\section{ACTIVATION AND COOPERATION OF MULTIPLE PRO-ANGIO-MORPHOGENETIC PATHWAYS}

The emergence of the chemokine system as a key signal during CNS development and vascularization raises the issue of a possible functional interaction with other pro-angiogenic pathways such as the canonical $\mathrm{Wnt} / \beta$-catenin pathway, whose involvement in regulating vascular morphogenesis has already been described, together with a CNS-specific angiogenic, and barriergenesis function in concert with other signaling pathways (Daneman et al., 2009; Dejana, 2010; Reis and Liebner, 2013). As suggested by studies on the effect of RG cells ablation, a cooperative effect of CXCL12/CXCR4-Wnt/ $\beta$-catenin exists during brain vascularization. In fact, in absence of RG cells, a significant reduction has been observed of cortical thickness, and the regression of nascent brain vessels, via the inhibition of EC Wnt signaling in a contact and stage-dependent manner (Ma et al., 2013). Moreover, the interaction between $\mathrm{Wnt} / \beta$-catenin signaling and the chemokine receptors CXCR4 and CXCR7 leads to a coordinated cell migration via differential receptor regulation (Aman and Piotrowski, 2008); this same cooperation may generate localized molecular cues, inducing differentiation of $\mathrm{BBB}$ properties and cortex microvessel maturation (Engelhardt and Liebner, 2014).

In conclusion, this study, carried out during human cerebral cortex development, supports the concept of an involvement of RG cells in the synchronized regulation of neuro-vascular patterning and early BBB differentiation. According to our model (Figures 1A-C), this may take place thanks to the unique, spatial distribution of RG cells, the varicosity/MV/CXCL12/Cx43 machinery, and the help of an overlapping repertoire of signaling molecules (Carmeliet and Tessier-Lavigne, 2005; Vasudevan and Bhide, 2008; Tam and Watts, 2010).

\section{AUTHOR CONTRIBUTIONS}

Mariella Errede Substantial contribution to the design of the work, acquisition, electron microscopy analysis, interpretation of data. Francesco Girolamo Substantial contribution to the design of the work; acquisition, confocal microscopy analysis, interpretation of data. Marco Rizzi Substantial contribution to acquisition and confocal microscopy analysis, interpretation of data. Mirella Bertossi Substantial contribution to interpretation of electron microscopy data and revising the work critically for important intellectual content. Luisa Roncali Substantial contribution in revising the work critically for important intellectual content and final approval of the version to be published. Daniela Virgintino Substantial contributions to the conception of the work, drafting the work and revising it critically; final approval of the version to be published.

\section{ACKNOWLEDGMENTS}

We are indebted to W. B. Stallcup (The Sanford-Burnham Institute for Molecular Medicine, La Jolla, CA, USA) for polyclonal anti-NG2/CSPG4 D2 antiserum and to E. Maiorano (Department of Emergency and Organ Transplantation, Pathological Anatomy Unit, Faculty of Medicine, University of Bari, Bari, Italy) for histological, control sections. Mary Victoria Pragnell is gratefully acknowledged for language help. This work has been funded by grants from Fondazione Cassa di Risparmio di Puglia to Daniela Virgintino and from the Italian Ministry of the University and Scientific Research (MIUR), Progetto di Ricerca d'Interesse Nazionale to Luisa Roncali.

\section{REFERENCES}

Aman, A., and Piotrowski, T. (2008). Wnt/beta-catenin and Fgf signaling control collective cell migration by restricting chemokine receptor expression. Dev. Cell 15, 749-761. doi: 10.1016/j.devcel.2008.10.002

Bär, T. (1980). The vascular system of the cerebral cortex. Adv. Anat. Embryol. Cell Biol. 59, 1-62. doi: 10.1007/978-3-642-67432-7_1

Bentivoglio, M., and Mazzarello, P. (1999). The history of radial glia. Brain Res. Bull. 49, 305-315. doi: 10.1016/S0361-9230(99)00065-9

Borrell, V., and Marín, O. (2006). Meninges control tangential migration of hemderived Cajal-Retzius cells via CXCL12/CXCR4 signaling. Nat. Neurosci. 9, 1284-1293. doi: 10.1038/nn1764

Boulanger, C. M., and Tedgui, A. (2005). Dying for attention: microparticles and angiogenesis. Cardiovasc. Res. 67, 1-3. doi: 10.1016/j.cardiores.2005.05.001

Bussmann, J., Wolfe, S. A., and Siekmannm, A. F. (2011). Arterial-venous network formation during brain vascularization involves hemodynamic regulation of chemokine signaling. Development 138, 1717-1726. doi: 10.1242/dev.059881

Carmeliet, P., and Tessier-Lavigne, M. (2005). Common mechanisms of nerve and blood vessel wiring. Nature 436, 193-200. doi: 10.1038/nature03875

Choi, S. H., and Lapham, L. W. (1978). Radial glia In the human letal cerebrum a combined Golgi, immunofluorescent and electron microscopic study. Brain Res. 148, 295-311. doi: 10.1016/0006-8993(78)90721-7

Daneman, R., Agallin, D., Zhou, L., Kubnert, F., Kuo, J. C., and Barres, B. A. (2009). $\mathrm{Wnt} / \beta$-catenin signaling is required for CNS, but not non-CNS angiogenesis. Proc. Natl. Acad. Sci. U.S.A. 106, 641-646. doi: 10.1073/pnas.0805165106

Dejana, E. (2010). The role of wnt signaling in physiological and pathological angiogenesis. Circ. Res. 107, 943-952. doi: 10.1161/CIRCRESAHA.110.223750

Elias, L. A., Wang, D. D., and Kriegstein, A. R. (2007). Gap junction adhesion is necessary for radial migration in the neocortex. Nature 448, 901-907. doi: 10.1038 /nature 06063

Engelhardt, B., and Liebner, S. (2014). Novel insights into the development and maintenance of the blood-brain barrier. Cell Tiss. Res. 355, 687-699. doi: 10.1007/s00441-014-1811-2

Engelhardt, B., and Risau, W. (1995). “The development of the blood-brain barrier” in The Development of the Blood-Brain Barrier, eds J. Greenwood, D. Begley, M. Segal (London: Plenum), 10-100.

Errede, M., Benagiano, V., Girolamo, F., Flace, P., Bertossi, M., Roncali, L., et al. (2002). Differential expression of connexin43 in foetal, adult and tumourassociated human brain endothelial cells. Histochem. J. 34, 265-271. doi: 10.1023/A:1023344106815

Fedoroff, S., and Vernadakis, A. (1986). Astrocytes. Development, Morphology and Regional Specialization of Astrocytes. London: Academic Press.

Frühbeis, C., Fröhlich, D., and Krämer-Albers, E. M. (2012). Emerging roles of exosomes in neuron-glia communication. Front. Physiol. 3:119. doi: $10.3389 /$ fphys.2012.00119 
Fujita, M., Cha, Y. R., Pham, V. N., Sakurai, A., Roman, B. L., Gutkind, J. S., et al. (2011). Assembly and patterning of the vascular network of the vertebrate hindbrain. Development 138, 1705-1715. doi: 10.1242/dev.058776

Giaume, C., Leybaert, L., Naus, C. C., and Sáez, J. C. (2013). Connexin and pannexin hemichannels in brain glial cells: properties, pharmacology, and roles. Front. Pharmacol. 4:88. doi: 10.3389/fphar.2013.00088

György, B., Szabó, T. G., Pásztói, M., Pál, Z., Misják, P., Aradi, B., et al. (2011). Membrane vesicles, current state-of-the-art: emerging role of extracellular vesicles. Cell. Mol. Life Sci. 68, 2667-2688. doi: 10.1007/s00018-0110689-3

Howard, B., Chen, Y., and Zecevic, N. (2006). Cortical progenitor cells in the developing human telencephalon. Glia 53, 57-66. doi: 10.1002/glia.20259

Howard, B. M., Mo, Z., Filipovic, R., Moore, A. R., Antic, S. D., and Zecevic, D. (2008). Radial glia cells in the developing human brain. Neuroscientist 14, 459-473. doi: 10.1177/1073858407313512

Kalra, H., Simpson, R. J., Ji, H., Aikawa, E., Altevogt, P., Askenase, P., et al. (2012). Vesiclepedia: a compendium for extracellular vesicles with continuous community annotation. PLoS Biol. 10:e1001450. doi: 10.1371/journal.pbio.1001450

Kawamoto, T., Ohga, N., Akiyama, K., Hirata, N., Kitahara, S., Maishi, N., et al. (2012). Tumor-derived microvesicles induce proangiogenic phenotype in endothelial cells via endocytosis. PLoS ONE 7:e34045. doi: 10.1371/journal.pone.0034045

Kriegstein, A., and Alvarez-Buylla, A. (2009). The glial nature of embryonic and adult neural stem cells. Annu. Rev. Neurosci. 32, 149-184. doi: 10.1146/annurev.neuro.051508.135600

Li, G., Adesnik, H., Li, J., Long, J., Nicoll, R. A., Rubenstein, J. L., et al. (2008). Regional distribution of cortical interneurons and development of inhibitory tone are regulated by Cxcl12/Cxcr4 signaling. J. Neurosci. 28, 1085-1098. doi: 10.1523/JNEUROSCI.4602-07.2008

Liebner, S., and Plate, K. H. (2010). Differentiation of the brain vasculature: the answer came blowing by the Wnt. J. Angiogenesis Res. 2, 1-10. doi: 10.1186/2040-2384-2-1

Ma, S., Kwon, H. J., Johng, H., Zang, K., and Huang, Z. (2013). Radial glial neural progenitors regulate nascent brain vascular network stabilization via inhibition of Wnt signaling. PLoS Biol. 11:e1001469. doi: 10.1371/journal.pbio. 1001469

Machtaler, S., Dang-Lawson, M., Choi, K., Jang, C., Naus, C. C., and Matsuuchi, L. (2011). The gap junction protein $\mathrm{Cx} 43$ regulates B-lymphocyte spreading and adhesion. J. Cell Sci. 124, 2611-2621. doi: 10.1242/jcs.089532

Malatesta, P., and Götz, M. (2013). Radial glia - from boring cables to stem cell stars. Development 140, 483-486. doi: 10.1242/dev.085852

Malatesta, P., Hartfuss, E., and Götz, M. (2000). Isolation of radial glial cells by fluorescent-activated cell sorting reveals a neuronal lineage. Development 127 5253-5263.

Marin-Padilla, M. (1985). Early vascularization of the embryonic cerebral cortex: Golgi and electron microscopic studies. J. Comp. Neurol. 241, 237-249. doi: $10.1002 /$ cne. 902410210

Marín-Padilla, M. (2012). The human brain intracerebral microvascular system: development and structure. Front. Neuroanat. 6:38. doi: 10.3389/fnana.2012.00038

Martinez, M. C., and Andriantsitohaina, R. (2011). Microparticles in angiogenesis: therapeutic potential. Circ. Res. 109, 110-119. doi: 10.1161/CIRCRESAHA.110.233049

Matsuuchi, L., and Naus, C. C. (2013). Gap junction proteins on the move: connexins, the cytoskeleton and migration. Biochim. Biophys. Acta 1828, 94-108. doi: 10.1016/j.bbamem.2012.05.014

Muralidharan-Chari, V., Clancy, J. W., Sedgwick, A., and D'Souza-Schorey, C. (2010). Microvesicles: mediators of extracellular communication during cancer progression. J. Cell Sci. 123, 1603-1611. doi: 10.1242/jcs.064386

Nagy, J. I., Dudek, F. E., and Rash, J. E. (2004). Update on connexins and gap junctions in neurons and glia in the mammalian nervous system. Brain Res. Brain Res. Rev. 47, 191-215. doi: 10.1016/j.brainresrev.2004.05.005

Nielsen, M. S., Nygaard Axelsen, L., Sorgen, P. L., Verma, V., Delmar, M., and Holstein-Rathlou, N. H. (2012). Gap junctions. Compr. Physiol. 2, 1981-2035. doi: 10.1002/cphy.c110051

Paredes, M. F., Li, G. N., Berger, O., Baraban, S. C., and Pleasure, S. J. (2006). Stromal-derived factor-1 (CXCL12) regulates laminar position of CajalRetzius cells in normal and dysplastic brains. J. Neurosci. 26, 9404-9412. doi: 10.1523/JNEUROSCI.2575-06.2006
Peng, H., Kolb, R., and Kennedy, J. E. (2007). Differential expression of CXCL12 and CXCR4 during human fetal neural progenitor cell differentiation. J. Neuroimmun. Pharmacol. 2, 251-258. doi: 10.1007/s11481-007-9081-3

Proia, P., Schiera, G., Mineo, M., Ingrassia, A. M., Santoro, G., Savettieri, G., et al. (2008). Astrocytes shed extracellular vesicles that contain fibroblast growth factor-2 and vascular endothelial growth factor. Int. J. Mol. Med. 21, 63-67. doi: 10.3892/ijmm.21.1.63

Quaegebeur, A., Lange, C., and Carmeliet, P. (2011). The neurovascular link in health and disease: molecular mechanisms and therapeutic implications. Neuron 71, 406-424. doi: 10.1016/j.neuron.2011.07.013

Rakic, P. (1971). Neuron-glia relationship during granule cell migration in developing cerebellar cortex. A Golgi and electronmicroscopic study in Macacus Rhesus. J. Comp. Neurol. 141, 283-312. doi: 10.1002/cne.901410303

Rakic, P. (1972). Mode of cell migration to the superficial layers of fetal monkey neocortex. J. Comp. Neurol. 145, 61-83. doi: 10.1002/cne.901450105

Rakic, P. (2007). The radial edifice of cortical architecture. Brain Res. Rev. 55, 204-219. doi: 10.1016/j.brainresrev.2007.02.010

Ramón y Cajal, S. (1904). Textura del Sistema Nervioso del Hombre y de los Vertebrados. Madrid: Moya.

Reis, M., and Liebner, S. (2013). Wnt signaling in the vasculature. Exp. Cell Res. 319, 1317-1323. doi: 10.1016/j.yexcr.2012.12.023

Rickmann, M., and Wolff, J. R. (1985). Prenatal gliogenesis in the neopallium of the rat. Adv. Anat. Embryol. Cell Biol. 93, 37-66.

Risau, W., Gautschi-Sova, P., and Bohlen, P. (1988). Endothelial cell growth factors in embryonic and adult chick brain are related to human acidic fibroblast growth factor. EMBO J. 7, 959-962.

Risau, W., and Wolburg, H. (1990). Development of the blood-brain barrier. Trends Neurosci. 13, 174-178. doi: 10.1016/0166-2236(90)90043-A

Schajnovitz, A., Itkin, T., D’Uva, G., Kalinkovich, A., Golan, K., Ludin, A., et al. (2011). CXCL12 secretion by bone marrow stromal cells is dependent on cell contact and mediated by connexin-43 and connexin-45 gap junctions. Nat. Immunol. 12, 391-398. doi: 10.1038/ni.2017

Siegenthaler, J. A., Ashique, A. M., Zarbalis, K., Patterson, K. P., Hecht, J. H., Kane, M. A., et al. (2009). Retinoic acid from the meninges regulates cortical neuron generation. Cell 139, 597-609. doi: 10.1016/j.cell.2009.10.004

Stehberg, J., Moraga-Amaro, R., Salazar, C., Becerra, A., Echeverría, C., Orellana, J. A., et al. (2012). Release of gliotransmitters through astroglial connexin 43 hemichannels is necessary for fear memory consolidation in the basolateral amygdala. FASEB J. 26, 3649-3657. doi: 10.1096/fj.11-198416

Strasser, G. A., Kaminker, J. S., and Tessier-Lavigne, M. (2010). Microarray analysis of retinal endothelial tip cells identifies CXCR4 as a mediator of tip cell morphology and branching. Blood 115, 5102-5110. doi: 10.1182/blood-200907-230284

Stumm, R., and Höllt, V. (2007). CXC chemokine receptor 4 regulates neuronal migration and axonal pathfinding in the developing nervous system: implications for neuronal regeneration in the adult brain. J. Mol. Endocrinol. 38, 377-382. doi: 10.1677/JME-06-0032

Stumm, R. K., Zhou, C., Ara, T., Lazarini, F., Dubois-Dalcq, M., Nagasawa, T., et al. (2003). CXCR4 regulates interneuron migration in the developing neocortex. J. Neurosci. 23, 5123-5130.

Tam, S. J., and Watts, R. J. (2010). Connecting vascular and nervous system development: angiogenesis and the blood-brain barrier. Annu. Rev. Neurosci. 33, 379-408. doi: 10.1146/annurev-neuro-060909-152829

Tiveron, M. C., and Cremer, H. (2008). CXCL12/CXCR4 signalling in neuronal cell migration. Curr. Opin. Neurobiol. 18, 237-244. doi: 10.1016/j.conb.2008. 06.004

Tiveron, M. C., Rossel, M., Moepps, B., Zhang, Y. L., Seidenfaden, R., and Favor, J., et al (2006). Molecular interaction between projection neuron precursors and invading interneurons via stromal-derived factor 1 (CXCL12)/CXCR4 signaling in the cortical subventricular zone/intermediate zone. J. Neurosci. 26, 13273-13278. doi: 10.1523/JNEUROSCI.4162-06.2006

Unoki, N., Murakami, T., Nishijima, K., Ogino, K., van Rooijen, N., and Yoshimura, N. (2010). SDF-1/CXCR4 contributes to the activation of tip cells and microglia in retinal angiogenesis. Invest. Ophthalmol. Vis. Sci. 51, 3362-3371. doi: 10.1167/iovs.09-4978

Vasudevan, A., and Bhide, P. G. (2008). Angiogenesis in the embryonic CNS: a new twist on an old tale. Cell Adh. Migr. 2, 167-169. doi: 10.4161/cam.2.3.6485

Virgintino, D., Errede, M., Rizzi, M., Girolamo, F., Strippoli, M., Wälchli, T., et al. (2013). The CXCL12/CXCR4/CXCR7 ligand-receptor system regulates 
neuro-glio-vascular interactions and vessel growth during human brain development. J. Inherit. Metab. Dis. 36, 455-466. doi: 10.1007/s10545-0129574-y

Virgintino, D., Maiorano, E., Errede, M., Vimercati, A., Greco, P., Selvaggi, L., et al. (1998). Astroglia-microvessel relationship in the developing human telencephalon. Int. J. Dev. Biol. 42, 1165-1168.

Virgintino, D., Robertson, D., Errede, M., Benagiano, V., Bertossi, M., Ambrosi, G., et al. (2001). Expression of the gap junction protein connexin43 in human telencephalon microvessels. Microvasc. Res. 62, 435-439. doi: 10.1006/mvre.2001.2345

Weissman, T., Noctor, S. C., Clinton, B. K., Honig, L. S., and Kriegstein, A. R. (2003). Neurogenic radial glial cells in reptile, rodent and human: from mitosis to migration. Cereb. Cortex 13, 550-559. doi: 10.1093/cercor/13.6.550

Xu, L., Tang, X., Wang, Y., Xu, H., and Fan, X. (2014). Radial glia, the keystone of the development of the hippocampal dentate gyrus. Mol. Neurobiol. doi: 10.1007/ s12035-014-8692-y. [Epub ahead of print].

Zhou, J. Z., and Jiang, J. X. (2014). Gap junction and hemichannel-independent actions of connexins on cell and tissue functions - An update. FEBS Lett. 588, 1186-1192. doi: 10.1016/j.febslet.2014.01.001
Conflict of Interest Statement: The authors declare that the research was conducted in the absence of any commercial or financial relationships that could be construed as a potential conflict of interest.

Received: 15 July 2014; paper pending published: 11 August 2014; accepted: 25 September 2014; published online: 15 October 2014.

Citation: Errede M, Girolamo F, Rizzi M, Bertossi M, Roncali L and Virgintino D (2014) The contribution of CXCL12-expressing radial glia cells to neuro-vascular patterning during human cerebral cortex development. Front. Neurosci. 8:324. doi: 10.3389/fnins.2014.00324

This article was submitted to Neurogenomics, a section of the journal Frontiers in Neuroscience.

Copyright (C) 2014 Errede, Girolamo, Rizzi, Bertossi, Roncali and Virgintino. This is an open-access article distributed under the terms of the Creative Commons Attribution License (CC BY). The use, distribution or reproduction in other forums is permitted, provided the original author(s) or licensor are credited and that the original publication in this journal is cited, in accordance with accepted academic practice. No use, distribution or reproduction is permitted which does not comply with these terms. 